\title{
Human Rights And HealthCaRe ${ }^{(*)}$
}

\author{
Elizabeth Wicks, \\ Oxford and Portland, Oregon: Hart Publishing, 2007
}

Octávio L. M. Ferraz ${ }^{(* *)}$

\begin{abstract}
Elizabeth Wicks adota a visão, primeiramente defendida na Inglaterra por Kennedy e Grubb, que o direito sanitário "é um subgrupo dos direitos humanos" ("is a subset of human rights law"). Direitos humanos supostamente conferem a "unidade conceitual" ("conceptual unity"), isto é, a "coerência interna" ("internal coherence") que é necessária para o Direito Sanitário consolidar sua reivindicação de autonomia como área jurídica ao invés de permanecer como a "versão acadêmica do cuco"(1) "academic version of the cuckoo"), usando conceitos de outras áreas do Direito sem ter uma identidade para si. Visto que proeminentes especialistas em Direito Sanitário não estão convencidos dessa visão (e. g. Mason and Laurie, Mason and McCall Smith's Law and Medical Ethics, OUP, 2006), o objetivo da autora é evidenciá-la "ao catalogar a miríade de influências da esfera dos direitos humanos introduzida no Direito Sanitário nos últimos anos e argumentado em favor da priorização dos direitos e da autonomia individual como um valor subjacente no Direito Sanitário inglês" ("cataloguing the myriad of influences introduced into medical law from the sphere of human rights law in recent years and by arguing in favour of the prioritisation of individual autonomy and rights as an underlying value in English medical law" - p. 3).
\end{abstract}

Essas declarações na introdução do livro parecem levantar três tipos diferentes questões sobre a potencial relação entre direitos humanos e assistência à saúde. A primeira, mais descritiva, é se a incorporação da Convenção Européia de Direitos Humanos pelo Human Rights Act britânico de 1998 tem tido uma influência significativa no Direito Sanitário. Outra, mais

${ }^{*}$ ) NOTA DO EDITOR: Texto produzido originariamente no idioma Inglês. A versão para o Português foi revisada pelo próprio autor, que incluiu notas de rodapé para melhor compreensão do leitor. A versão original do texto está publicada na seqüência.

$\left.{ }^{(* *}\right)$ Professor assistente, Escola de Direito da Universidade de Warwick (EUA). E-mail: $<$ o.l.m.ferraz@warwick.ac.uk>. Recebido em 07.08.09.

(1) Do inglês cuckoo, pássaro notável por colocar seus ovos no ninho de outros pássaros. 
conceitual, é se os direitos humanos realmente provêem uma unidade conceitual para o tema do Direito Sanitário. A terceira, mais prescritiva, é se os direitos humanos deveriam constituir o valor subjacente predominante em todas as questões do direito sanitário.

As duas últimas questões poderiam muito bem ter sido assuntos de capítulos autônomos e mais gerais; mas, a autora optou por lidar com elas ao longo da discussão de tópicos específicos. Em onze extensos capítulos cobrindo os principais temas do Direito Sanitário, tais como negligência médica (Capítulo 3), consentimento para tratamento (Capítulo 4), confidencialidade (Capítulo 6), aborto (Capítulo 9) e eutanásia (Capítulos 11 e 12), a autora apresenta uma narração descritiva e uma análise crítica do atual estado do Direito Sanitário e de como os direitos humanos têm (ou não têm em alguns casos) sido considerados em decisões judiciais nas cortes britânicas.

Particularmente, interessantes são os capítulos sobre consentimento para tratamento médico (Capítulo 4) e o direito à vida no fim da vida (Capítulo 11 ), em que temas de direitos humanos são mais indiscutivelmente relacionados e têm, em grande medida, aparecido no Direito Sanitário (embora por meio da linguagem da ética médica) antes da promulgação do Human Rights Act. Sobre o tema do consentimento, a autora corrobora a tese de que sua exigência é baseada no direito à autonomia (ou autodeterminação) do paciente, citando dispositivos da Convenção Européia de Direitos Humanos (sigla em inglês $E C H R$ ) e da menos conhecida Convenção Européia sobre Direitos Humanos e Biomedicina (sigla em inglês ECHRB) para sustentar sua posição. Ela também argumenta fortemente que "a autonomia do paciente ... terá sido violada independentemente de qualquer dano que venha a resultar do tratamento" ("the patient's autonomy ... will have been infringed regardless of whether any injury results from the treatment") quando informações relevantes necessárias para o paciente fazer sua escolha (consentimento informado) são omitidas pelo médico (p. 81). Ela critica, assim, a necessidade de materialização do dano para que o paciente possa fazer uso do instituto legal ação reparatória por não proteger suficientemente o direito à autonomia. Embora concordemos que a autonomia é violada independentemente da ocorrência de danos físicos, acreditamos que a autora talvez tenha confiado excessivamente na ação reparatória como remédio apropriado para proteção da autonomia. Por que, poder-se-ia perguntar, a compensação seria a resposta legal adequada para uma violação à autonomia do paciente?

No Capítulo 11, após mostrar grande domínio de assuntos científicos em torno da morte e mostrando os complicados problemas que ela apresenta para a Ética e o Direito, a autora discute o famoso caso Bland ([1993] 1 All ER 831), "talvez o caso paradigmático no direito sanitário inglês" (p. 227) ("perhaps the landmark case in English medical law"), no qual a seção judi- 
ciária da Casa dos Lordes $^{(2)}$ autorizou médicos a interromperem a vida de Tony Bland, uma das vítimas do famoso acidente de Hillsborough em 1989, no qual torcedores do time de futebol Liverpool foram esmagados contra as grades do estádio durante uma ação desastrada da polícia em controlar a torcida. Bland, que sofrera dano cerebral e estava em estado vegetativo no hospital, podia no entanto respirar sem o auxílio de aparelhos, e assim estava fazia anos, quando a Casa dos Lordes autorizou os médicos a suspender a hidratação e alimentação artificial e, desta forma, causar-lhe uma morte lenta por inanição.

Embora o caso tenha sido julgado antes do Human Rights Act entrar em vigor, os tribunais continuaram aplicando seus princípios posteriormente, por exemplo, no caso NHS Trust ([2001] 2 WLR 942). Wicks questiona pertinentemente "como pode a interrupção de um tratamento essencial à manutenção da vida, tal como a nutrição e hidratação artificial, ser consistente com o dever estatal de proteger o direito à vida de todas as pessoas, incluindo aquelas em estado vegetativo?" ("how can the withdrawal of essential life-sustaining treatment such as ANH be consistent with the state's duty to protect the right to life of all persons, including those in PVS?" - p. 245). Como ela corretamente nota, a decisão do caso NHS Trust lida de forma insatisfatória com esse importante tema.

Argumentados de maneira menos convincente, em nosso ponto de vista, são os Capítulos 2 e 3, talvez devido a sua menos óbvia e incontroversa conexão com os direitos humanos. No Capítulo 3, a autora discute o campo da negligência médica. O tom do capítulo é de que o atual sistema é excessivamente baseado na opinião de profissionais médicos na determinação da culpa (o infame teste Bolam) ${ }^{(3)}$ e isso acontece em detrimento dos direitos do paciente. O mesmo é dito do difícil teste do nexo de causalidade e um isolado caso no qual esse teste foi relativizado (Chester $v$ Ashfar) é aclamado como "encorajador do ponto de vista dos direitos humanos" ("encouraging from a human rights perspective" — p. 50). Mas, esse argumento não é muito mais desenvolvido neste capítulo. Por que e como as regras sobre o

(2) A Casa dos Lordes, como se sabe, é a segunda câmara do Parlamento inglês, não eleita e, no que alguns entendem ser uma anomalia constitucional em face do princípio da separação dos poderes, alberga também o mais alto tribunal judiciário, formado por doze membros chamados de Law Lords (Lordes do Direito). Os Law Lords, por convenção, não participam de debates sobre legislação que poderiam afetar suas decisões judiciais, mas são, para todos os efeitos, membros do Parlamento e, portanto, do Poder Legislativo e Judiciário a um só tempo. A partir de 2009 essa anomalia cessará com a criação da Suprema Corte britânica, que será autônoma e cujos membros não mais serão membros do Parlamento.

(3) O teste Bolam foi concebido em caso paradigmático de 1957 - Bolam v Friern Hospital Management Committee ([1957] 1 WLR 583) - que é até hoje o leading case em ações de indenização por negligência profissional. Ele estabelece o princípio, muito criticado por ativistas, segundo o qual o médico não pode ser considerado negligente se uma "escola de opinião médica responsável" ("a body of responsible medical opinion") , ainda que minoritária, der suporte à conduta do médico sendo processado. 
nexo de causalidade e a culpa estão em conflito com os direitos humanos do paciente? Quais direitos humanos exatamente estão envolvidos aqui? A autora parece presumir que a reparação do dano derivado de assistência médica é um direito humano e, conseqüentemente, quaisquer dificuldades colocadas pelas tradicionais regras da responsabilidade civil estão em conflito com aquele direito. Pode ser esse o caso, mas, em nossa visão, demandaria uma fundamentação mais sólida que aquela apresentada no livro.

O Capítulo 2 discute questões importantes e talvez das mais controversas em termos de direitos humanos: se há um direito positivo (uma pretensão) a tratamento médico e o intricado tema da eqüidade na alocação de recursos (p. 23-27) que isso inevitavelmente levanta. A autora corretamente reconhece a importância do tema ao colocá-lo logo no começo do livro e qualificá-lo como "um tema preliminar" ("a preliminary issue" — p. 17), dizendo que "a integralidade da [proteção de outros direitos humanos ligados à saúde] pressupõe que o paciente tem acesso ao tratamento médico necessário" ("the entirety of [the protection of other human rights engaged in health] presupposes that the patient has access to the necessary medical treatment" - p. 17). É feita uma longa e interessante crítica ao famoso critério para alocação de recursos atualmente usado no serviço público inglês, os QALYs (Quality Adjusted Life Years), mas pouco é dito a respeito dos argumentos a favor dessa metodologia e outros índices de análise de custo-efetividade como, por exemplo, os DALYs (Disability Adjusted Life Years), que foi proposta como um avanço em relação aos $Q A L Y s$ e tem sido adotado em um grande número de países (para um bom trabalho com artigos sobre esse tema ver Anand, Peter and Sen (eds), Public Health, Ethics and Equity, OUP, 2004). A solução própria da autora para esse problema da alocação de recursos escassos em saúde, o qual ela chama de "mérito terapêutico" ("therapeutic merit"), no qual o paciente com maior necessidade clínica deve receber o tratamento ("the patient in greatest clinical need must receive the treatment" - p. 26), poderia também ser melhor desenvolvida e defendida dada a complexidade e o potencial de controvérsia que apresenta. De qualquer forma, a autora termina o capítulo reconhecendo não somente que "o direito a tratamento é o mais controverso entre todos os direitos relacionados à assistência à saúde" ("a right to treatment is the most controversial of all the healthcare rights" - p. 36), mas, também, que tal direito seria "simplesmente irrealista" ("simply unrealistic" - p. 36), o que nos leva a pensar quão danoso isso é para sua tese de que direitos humanos deveriam ser o valor subjacente de todo Direito Sanitário.

Em outros capítulos, a consideração de que os direitos humanos são o principal e unificador valor no Direito Sanitário parece mais persuasiva, por exemplo, no tratamento de pacientes incapazes e vulneráveis (Capítulo 5), a confidencialidade de informações médicas (Capítulo 6), o controle sobre o próprio corpo e partes do corpo durante e após a vida (Capítulo 7), aborto (Capítulo 9) e eutanásia (Capítulo 12). Mas as dificuldades levantadas pelo 
estabelecimento de uma persuasiva conexão entre Direito Sanitário e direitos humanos nos dois tópicos acima discutidos (negligência e direito do paciente a tratamento), os quais juntos representam uma parte significativa do Direito Sanitário, lançam dúvidas sobre os objetivos conceituais e prescritivos do projeto. Se não há no Reino Unido um direito humano ao tratamento, como defendem muitos e reconhece a autora, e se a negligência médica não é uma questão de direitos humanos, mas, simplesmente um tema de responsabilidade civil (como sustentam alguns), a tese de que os direitos humanos provêem a unidade conceitual do Direito Sanitário, e deveria ser o valor subjacente em todas as áreas, parece não estar provada, ou pelo menos está sobrevalorizada. Talvez seria mais plausível alegar simplesmente que os direitos humanos têm um significativo impacto no Direito Sanitário, mas isso seria igualmente verdadeiro para outras áreas do Direito, tais como a trabalhista, penal, administrativa etc.

Embora não totalmente convincente em questões conceituais e prescritivas sobre a relação entre direitos humanos e Direito Sanitário, o livro de Wick oferece um abrangente e completo relato e análise dos principais tópicos do Direito Sanitário à luz de implicações reais e potenciais em termos de direitos humanos. Conseqüentemente, é uma boa fonte para qualquer um interessado nessas intricadas e importantes questões. 